\title{
Optimal Use of Wire-Assisted Techniques and Precut Sphincterotomy
}

\author{
Tae Hoon Lee and Sang-Heum Park \\ Division of Gastroenterology, Department of Internal Medicine, Soon Chun Hyang University Cheonan Hospital, Soon Chun Hyang University \\ College of Medicine, Cheonan, Korea
}

Various endoscopic techniques have been developed to overcome the difficulties in biliary or pancreatic access during endoscopic retrograde cholangiopancreatography, according to the preference of the endoscopist or the aim of the procedures. In terms of endoscopic methods, guidewire-assisted cannulation is a commonly used and well-known initial cannulation technique, or an alternative in cases of difficult cannulation. In addition, precut sphincterotomy encompasses a range of available rescue techniques, including conventional precut, precut fistulotomy, transpancreatic septotomy, and precut after insertion of pancreatic stent or pancreatic duct guidewire-guided septal precut. We present a literature review of guidewire-assisted cannulation as a primary endoscopic method and the precut technique for the facilitation of selective biliary access. Clin Endosc 2016;49:467-474

Key Words: Cholangiopancreatography, endoscopic retrograde; Precut; Guidewire; Catheterization

\section{INTRODUCTION}

Endoscopic retrograde cholangiopancreatography (ERCP) is an essential technique for the treatment of pancreatobiliary diseases. However, therapeutic ERCP is still associated with various complications, such as post-ERCP pancreatitis (PEP), cholangitis, hemorrhage, cholecystitis, and perforation. Moreover, for safe and successful ERCP procedures, initial selective biliary or pancreatic cannulation is necessary to reduce the potential complications. Even when performed by experts, selective biliary cannulation is unsuccessful in $5 \%$ to $10 \%$ of patients, despite the various endoscopic techniques available. ${ }^{1}$

To overcome difficult cannulation, without increasing the incidence of complications, various endoscopic techniques and devices have been devised. We present a literature review

Received: July 14, 2016 Revised: August 19, 2016

Accepted: August 19, 2016

Correspondence: Tae Hoon Lee

Division of Gastroenterology and Hepatology, Department of Internal Medicine, Soon Chun Hyang University Cheonan Hospital, Soon Chun Hyang University College of Medicine, 31 Suncheonhyang 6-gil, Dongnam-gu, Cheonan 31151, Korea

Tel: +82-41-570-3662, Fax: +82-41-574-5762, E-mail: thlee9@schmc.ac.kr

(cc) This is an Open Access article distributed under the terms of the Creative Commons Attribution Non-Commercial License (http://creativecommons.org/ licenses/by-nc/3.0) which permits unrestricted non-commercial use, distribution, and reproduction in any medium, provided the original work is properly cited. of primary wire-guided cannulation (WGC) techniques (technique of insertion of guidewire selectively through catheter or papillotome before injection of contrast) and precut sphincterotomy (the cutting from the papillary orifice or on the papillary roof) for facilitating selective biliary access without increasing complications in difficult biliary cannulation.

\section{GUIDEWIRE-GUIDED CANNULATION TECHNIQUES}

A guidewire is a useful and essential accessory during ERCP or interventional endoscopic ultrasonography (EUS). The choice of guidewire depends on the type of procedure or the preference of the endoscopist. Recent reports have suggested that the use of a WGC technique could increase the success rate of selective biliary cannulation and reduce the frequency or severity of PEP, as compared to conventional contrast-assisted cannulation (CC), which uses contrast injection to access the bile duct. They also indicated that an early or initial attempt to apply the WGC technique, rather than just delayed or supportive use, could reduce procedural times., ${ }^{2,3}$

The CC technique is still the most commonly used initial cannulation technique. However, when CC techniques fail, WGC can be used as a useful alternative technique to facili- 
tate selective biliary cannulation. Siegel and Pullano ${ }^{4}$ reported the first use of WGC for selective bile duct cannulation. As a primary selective cannulation method, WGC can reduce complications caused by prolonged cannula manipulation or contrast injection into the pancreatic duct (PD). Theoretically, accessing the bile duct with the aid of a guidewire can reduce direct contact injury to the ampulla of Vater (AV) and $\mathrm{PD}$, and avoid the increase of hydrostatic pressure associated with contrast injection or papillary edema; thereby, reducing the development of PEP. ${ }^{5-15}$ A recent clinical guideline from the European Society of Gastrointestinal Endoscopy (ESGE) suggested the use of the WGC method for primary biliary cannulation, because WGC reduced the risk of $\mathrm{PEP}^{12}$

\section{Endoscopic technique}

WGC is a technically simple method. Normally, we use a hydrophilic tipped guidewire (diameter 0.035 or $0.025 \mathrm{inch}$ ), which is preloaded into a catheter or pull-type papillotome. The papillotome is oriented in the 11 to 12 oclock position on the $\mathrm{AV}$ and is bent to ensure correct alignment with the axis of the bile duct. As a direct contact method, following minimal insertion of the papillotome into the orifice of the $\mathrm{AV}$, the guidewire is carefully advanced into the common bile duct (CBD) under fluoroscopic guidance until it is seen to enter the $\mathrm{CBD}$. For the noncontact method, biliary access is achieved using the slightly protruding 2 to $3 \mathrm{~mm}$ tip of the guidewire on the papillotome to make smooth contact with the AV orifice. This noncontact method may avoid direct contact injury caused by the tip of the cannula or papillotome. If the PD is entered unintentionally, the guidewire is simply withdrawn and a further attempt is made to negotiate the CBD. If unintentional PD insertion occurs repeatedly, early switching to another appropriate method, such as double guidewire cannu- lation (DGC) or prophylactic pancreatic stent (PS) insertion followed by precut or transpancreatic septostomy, should be considered to facilitate selective access or minimize complications. However, the insertion frequency, procedure time, and the number of $\mathrm{PD}$ insertions of the guidewire, including retrials, have not been defined clearly. A recent ESGE guideline recommended pancreatic WGC in patients where selective biliary cannulation was difficult and repeated unintentional PD access occurred. ${ }^{12}$ It also recommended attempting the placement of a prophylactic PS in all patients in whom pancreatic guidewire-assisted attempts at biliary cannulation have failed.

\section{Clinical outcomes}

Compared with CC, the WGC technique increases the primary selective biliary cannulation rate and reduces the frequency or severity of PEP. Numerous randomized controlled trials (RCTs) have demonstrated the benefits of WGC (Table 1). ${ }^{6-11,15}$ A systematic review and meta-analysis also reported that WGC reduced the frequency or severity of PEP compared with CC. In addition, WGC was shown to be associated with a higher selective biliary cannulation rate. ${ }^{5,13} \mathrm{~A}$ recent meta-analysis of 12 RCTs showed that the WGC technique significantly reduced PEP compared with the CC technique (odds ratio [OR], $0.51 ; 95 \%$ confidence interval [CI], 0.32 to 0.82 ). In addition, the WGC technique was associated with greater primary cannulation success, fewer precut sphincterotomies, and no increase in other ERCP-related complications. ${ }^{5}$ Therefore, a recent ESGE guideline suggested that WGC should be employed as the initial selective cannulation method. ${ }^{12}$

The mechanisms by which WGC reduces the risk of PEP risk can be explained by several ways. Masci et al. ${ }^{14}$ identified

Table 1. Prospective Randomized Studies of Wire-Guided Cannulation and Conventional Cannulation

\begin{tabular}{|c|c|c|c|c|c|}
\hline \multirow{2}{*}{ Study } & \multirow{2}{*}{ No. } & \multirow{2}{*}{$\begin{array}{c}\text { Pancreatitis/accidental PD } \\
(\text { WGC vs. CC) })^{\text {a) }}\end{array}$} & \multicolumn{2}{|c|}{ Post-ERCP pancreatitis } & \multirow{2}{*}{$p$-value } \\
\hline & & & WGC & CC & \\
\hline Lella et al. $(2004)^{15}$ & $200 / 200$ & $0 / 82^{\mathrm{b})}, 5 / 113^{\mathrm{c})}$ & $0 / 197(0)$ & $8 / 195(4.1)$ & $<0.01$ \\
\hline Artifon et al. $(2007)^{9}$ & $150 / 150$ & $0 / 27^{\mathrm{d})}, 4 / 21^{\mathrm{e}}$ & $13 / 150(8.6)$ & $25 / 150(16.6)$ & 0.02 \\
\hline Bailey et al. $(2008)^{10}$ & $202 / 211$ & NA & $16 / 202(7.9)$ & $13 / 211(6.2)$ & 0.48 \\
\hline Katsinelos et al. $(2008)^{8}$ & $167 / 165$ & NA & $9 / 167(5.4)$ & $13 / 165(7.9)$ & 0.37 \\
\hline Lee et al. $(2009)^{11}$ & $150 / 150$ & $2 / 39^{\mathrm{f})}, 8 / 44^{\mathrm{g})}$ & $3 / 150(2)$ & $17 / 150(11.3)$ & 0.001 \\
\hline Mariani et al. $(2012)^{6}$ & $678 / 571$ & $15 / 99,8 / 95$ & $35 / 678(5.2)$ & $25 / 571(4.4)$ & 0.60 \\
\hline Kawakami et al. (2012) & $199 / 201$ & NA & $8 / 199(4.0)$ & $6 / 201(2.9)$ & NS \\
\hline
\end{tabular}

Values are presented as number (\%).

$\mathrm{PD}$, pancreatic duct cannulation or contrast injection; ERCP, endoscopic retrograde cholangiopancreatography; WGC, wire-guided cannulation; CC, conventional cannulation; NA, not available; NS, not significant.

${ }^{a)}$ Incidence of post-ERCP pancreatitis following accidental PD injection or cannulation in CC and WGC groups; $p$-value: ${ }^{\text {b) }}$ vs. ${ }^{c}$, $0.08 ;{ }^{d)}$ vs. ${ }^{\text {e) }}$, $0.05 ;{ }^{\mathrm{f})}$ vs. ${ }^{\mathrm{g})}, 0.09$ by Fisher exact test. 
several technical problems, including frequent contrast injections into the PD, difficult cannulation, precutting, pancreatic sphincterotomy, and balloon dilatation of the sphincter of Oddi, as risk factors for PEP in their meta-analysis study. The WGC technique may reduce the risk of pancreatitis by directly preventing unintentional contrast injection into the $\mathrm{PD}$ and pancreatic acinarization, facilitating early biliary cannulation, potentially limiting papillary trauma, or reducing the need to attempt precut sphincterotomies.

The definition of what constitutes "difficult" cannulation is still imprecise. Lee et al. ${ }^{11}$ defined difficult as the failure to achieve biliary access after attempting to do so for 10 minutes, or after more than five unintentional PD cannulations. Artifon et al. ${ }^{9}$ defined cannulation as difficult when 7 to 10 attempts were required to achieve successful biliary access. Recent studies suggested stricter criteria for difficult biliary cannulation. More RCTs are needed to establish cannulation difficulty criteria and arrive at a consensus on the definition of difficult. At present, more than five cannulation attempts, a cannulation time of more than 5 minutes, or unintentional cannulation of the $\mathrm{PD}$ on more than one occasion are considered to represent a difficult cannulation in experienced hands. ${ }^{12}$

Although WGC may reduce the risk of PEP, it does not do so in patients with suspected sphincter of Oddi dysfunction (SOD) or in patients who are subjected to unintentional WGC into the PD. In high-risk patients, such as those with SOD, repeated unintentional WGC into the PD may trigger PEP via mechanical injury or because of increases in hydrostatic pressure due to edematous obstruction of the AV. Therefore, when unintentional PD guidewire cannulation occurs, WGC followed by temporary placement of a PS may be preferable to WGC alone to prevent increases in pancreatic enzyme levels and reduce the frequency or severity of PEP, especially in high-risk patients. ${ }^{3}$ The ESGE also recommended the insertion of a prophylactic PS in all patients in whom pancreatic WGC attempts at biliary cannulation were made. ${ }^{12}$

\section{Double guidewire cannulation technique}

Since DGC was first described by Dumonceau et al., ${ }^{16}$ it has shown promise in overcoming difficult biliary cannulation and has been commonly used in cases of repeated unintentional PD cannulations. Technically, DGC may be an effective alternative to frequent unintentional PD cannulation. In DGC, while the previously inserted PD guidewire is in place, an attempt is made to insert another guidewire in the direction of the $\mathrm{CBD}$. The placement of the guidewire in the PD may facilitate selective biliary access, using another sphincterotome or a catheter in the same working channel as the first guidewire. The placement of the guidewire deep into the main PD may provide a variety of benefits, such as lifting the AV toward the working channel, straightening the PD and common channel, opening a stenotic papillary orifice, or potentially minimizing repeated guidewire insertions into the $\mathrm{PD} .^{17}$

Compared with the CC method, DGC has been suggested as a useful approach for overcoming difficult biliary cannulation. However, two prospective RCTs that compared the use of DGC versus CC methods in patients with difficult biliary cannulation reported conflicting results in terms of technical success and complications. ${ }^{18,19}$ Maeda et al. ${ }^{18}$ reported that the cannulation rate using the DGC technique was higher than with the CC method (93\% vs. 58\%, respectively), with no PEP. In contrast, Herreros de Tejada et al. ${ }^{19}$ showed that DGC was not superior to the CC technique in terms of technical success, and that PEP was more prevalent in the DGC group (17\% for DGC and $8 \%$ for CC). More large-scale comparative studies are required to clarify the controversy and the role of DGC versus CC.

A comparison of DGC with transpancreatic precut sphincterotomy revealed that both techniques were useful in cases of unintentional PD cannulation. ${ }^{20-22}$ The overall technical success and complications were not different in the reported studies. The use of a PS could significantly reduce the incidence of PEP. However, unlike transpancreatic sphincterotomy, persisting with DGC may extend the cannulation time. In cases of difficult cannulation or unintentional PD cannulation, to reduce the severity and incidence of PEP, a sequential algorithm (with crossover techniques) may be a useful alternative, rather than persisting with a single technique.

\section{Guidewire-related complications}

In addition to PEP, guidewire-related perforation may be an important complication. Although the tip of the guidewire is smooth and hydrophilic, perforation is a possibility. Common risk factors for guidewire-related perforation include Billroth II subtotal gastrectomy, endoscopic sphincterotomy, precut sphincterotomy, intramucosal injection of contrast agent, long procedure times, periampullary diverticulum, bile duct stricture, SOD, old age, and inexperience. ${ }^{23,24}$ In terms of the instruments used, perforation may also be associated with the texture of the guidewire itself and the flexibility of the tip. In the presence of these risk factors, perforation often occurs locally around the AV or proximal biliary obstruction. When biliary cannulation is difficult and the operator or assistants force the entry of the guidewire into the bile duct, guidewire-induced perforation may occur as a result of the AV edema or injury and inflammation of periampullary lesions. ${ }^{25,26}$ Moreover, the operator may not detect a microperforation created by the guidewire.

However, guidewire-related perforations are usually local microperforations and are clinically asymptomatic in most 
patients. Patients usually recover within 24 to 48 hours after conservative treatment, including fasting and broad-spectrum antibiotics. ${ }^{25,26}$ However, if the perforation is not detected at an early stage, the patient may develop abdominal pain or fever. During insertion of a drainage tube, catheter, or dilatator, further damage may unwittingly be done to the microperforation, increasing its size to the extent that surgery is required.

\section{PRECUT SPHINCTEROTOMY}

Precut sphincterotomy is now an essential rescue freehand technique when biliary cannulation proves difficult. Depending on the cutting direction, the conventional needle knife (NK) precut technique or precut fistulotomy (infundibulotomy) is commonly used. In the conventional NK approach, the precut starts at the papillary orifice and extends incrementally upwards. In the precut fistulotomy approach, the cut starts above the orifice and is extended upwards or downwards. In unintentional PD cannulation, transpancreatic septotomy or precut sphincterotomy, following the guidance of a previously inserted guidewire or PS, is also commonly used. However, there is limited data to aid in the selection of appropriate techniques. $^{27-36}$

Without regard to the technique used, numerous studies have reported primary technical success rates of precut sphincterotomy as high as $90 \%$ during the first attempt, despite failed or difficult primary cannulation, and secondary success rates of over $95 \%$ when the second attempts were conducted 2 to 3 days later, after AV edema or inflammation had subsided. The overall complication rates have been reported to vary from $1.9 \%$ to $34 \%$ after precut and from $7 \%$ to $14 \%$ after conventional sphincterotomy. Regarding PEP, the rates ranged from $2.1 \%$ to $14.9 \%$ and $1 \%$ to $10 \%$, respectively. ${ }^{27-34,37-44}$

Although precut is now a well-known effective rescue technique, NK sphincterotomy was previously considered a potentially dangerous procedure and has been directly implicated as a primary cause of PEP, especially when performed by less experienced endoscopists. Therefore, most authorities recommend that only experts should perform a precut. However, recent reports have shown that the precut-related complications, such as bleeding, PEP, and perforation, are similar to those associated with conventional sphincterotomy. ${ }^{27,41,44-48}$ A recent meta-analysis also showed that the early use of precut did not augment the risk of PEP, while it increased the successful selective cannulation rate compared with the conventional cannulation technique (Table 2). ${ }^{35,36,49-51}$

With regard to the effect of endoscopists' learning curves on the safety and success of precut, one study suggested that the rate of precut-related complications decreased significantly after the first 100 procedures had been performed, ${ }^{45}$ whereas the technical success of biliary access and the rate of PEP did not differ according to the endoscopists' experience. Another study also showed that the experience of the endoscopist did not influence the rate of complications such as PEP or bleeding with the use of precut fistulotomy in cases where

Table 2. Meta-Analyses Comparing Precut and Conventional Techniques in Difficult Biliary Cannulation

\begin{tabular}{|c|c|c|c|c|}
\hline Study & No. of patients & $\begin{array}{l}\text { Successful } \\
\text { biliary cannulation rate }\end{array}$ & $\begin{array}{l}\text { Overall complication } \\
\text { rate }^{\text {a) }}\end{array}$ & Pancreatitis rate $\mathrm{e}^{\mathrm{b})}$ \\
\hline $\begin{array}{l}\text { Cennamo et al. } \\
(2010)^{50}\end{array}$ & $\begin{array}{l}6 \text { RCTs } \\
442 \text { Precut } \\
524 \text { Conventional }\end{array}$ & $90 \%$ & $\begin{array}{l}5 \% \text { vs. } 6.3 \%(\mathrm{OR}, 0.78 \\
95 \% \mathrm{CI}, 0.44-1.37)\end{array}$ & $\begin{array}{l}2.5 \% \text { vs. } 5.3 \%(\mathrm{OR}, 1.20 ; 95 \% \mathrm{CI} \text {, } \\
0.54-2.69)\end{array}$ \\
\hline Gong et al. $(2010)^{51}$ & $\begin{array}{l}6 \text { RCTs } \\
439 \text { Precut } \\
520 \text { Conventional }\end{array}$ & $\begin{array}{l}89.3 \% \text { vs. } 78.1 \%(\mathrm{OR}, 2.05 \\
95 \% \mathrm{CI}, 0.64-6.63)\end{array}$ & $5.5 \%$ vs. $7.5 \%(p=0.21)$ & $\begin{array}{l}2.5 \% \text { vs. } 5.4 \%(\mathrm{OR}, 0.46 ; 95 \% \mathrm{CI} \text {, } \\
\quad 0.23-0.92 ; p=0.03)\end{array}$ \\
\hline $\begin{array}{l}\text { Choudhary et al. } \\
(2014)^{49}\end{array}$ & $\begin{array}{l}7 \text { RCTs } \\
478 \text { Precut } \\
554 \text { Conventional } \\
7 \text { Non-RCTs }(n=3,548)\end{array}$ & NS & $7.7 \%$ vs. $8.8 \%(p=0.34)$ & $\begin{array}{l}3.9 \% \text { vs. } 6.1 \%(p=0.07) \\
\text { For fistulotomy }(\mathrm{OR}, 0.27 ; 95 \% \\
\quad \text { CI, } 0.09-0.82 ; p=0.02)\end{array}$ \\
\hline $\begin{array}{l}\text { Navaneethan et al. } \\
(2014)^{36}\end{array}$ & $\begin{array}{l}7 \text { RCTs } \\
481 \text { Precut } \\
558 \text { Conventional }\end{array}$ & $\begin{array}{l}90 \% \text { vs. } 86.3 \%(\mathrm{OR}, 1.98 \\
95 \% \text { CI, } 0.70-5.65)\end{array}$ & $\begin{array}{l}6.2 \% \text { vs. } 6.9 \%(\mathrm{OR}, 0.85 \\
95 \% \mathrm{CI}, 0.51-1.41)\end{array}$ & $\begin{array}{l}3.9 \% \text { vs. } 6.1 \%(\mathrm{OR}, 0.58 ; 95 \% \mathrm{CI} \text {, } \\
0.32-1.05)\end{array}$ \\
\hline $\begin{array}{l}\text { Sundaralingam et al. } \\
(2015)^{35}\end{array}$ & $\begin{array}{l}5 \text { RCTs } \\
230 \text { Precut } \\
293 \text { Conventional }\end{array}$ & $\begin{array}{l}\text { In primary cannulation } \\
(\mathrm{OR}, 1.32 ; 95 \% \mathrm{CI} \\
1.04-1.68 ; p=0.01)\end{array}$ & $\begin{array}{l}\text { OR, } 1.01 ; 95 \% \text { CI, } 0.93- \\
1.09 ; p=0.18\end{array}$ & $\begin{array}{l}\text { For experienced endoscopists } \\
\text { (OR, } 0.29 ; 95 \% \text { CI, 0.10-0.86) } \\
\text { Overall (OR, 0.62; 95\% CI, } \\
0.28-1.31)\end{array}$ \\
\hline
\end{tabular}

RCT, randomized controlled trial; OR, odds ratio; CI, confidence interval; NS, not significant.

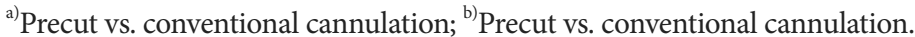


biliary cannulation was employed. ${ }^{27}$ However, the duration of a technically successful precut procedure showed a tendency to decrease after the first 50 precut fistulotomy procedures had been completed. A recent ESGE clinical guideline suggested that only endoscopists who achieved successful biliary access in more than $80 \%$ of cases using conventional cannulation techniques should use a precut; however, the guidelines were based on low-quality evidence. More studies are needed to define the level of experience required by operators to perform ERCP.

High frequencies of post-precut complications may be associated with extensive injuries caused by repeated or prolonged attempts to cannulate the bile duct or PD using standard methods before the precut is performed. Moreover, theoretically, the greater number of complications could be the result of direct thermal injury caused by the NK itself, especially during precutting, in which the incisions commence at the papillary orifice. However, making the NK incision on the papillary roof can prevent thermal injury to the PD and minimize the risk of pancreatitis. ${ }^{29,30,44}$ Nevertheless, a short papillary roof, a small or flat papilla, AV distortion caused by invasion of periampullary tumors or metastasis, or location of the $\mathrm{AV}$ on the inner center or ridge of a huge periampullary diverticulum, may preclude the use of precut fistulotomy. ${ }^{3,27}$

Huibregtse et al. ${ }^{47}$ reported that early application of precut increased technical success at the first attempt, as well as the overall technical success rate of cannulation, while reducing the rate of complications. Previous repeat cannulation attempts, prolonged cannulation times, or numerous insertions of a guidewire into the PD may increase the risk of PEP. Lee et al. ${ }^{27}$ showed that an excessive number $(>15)$ of cannulation attempts prior to precut fistulotomy were a risk factor for the development of PEP in a multivariate analysis (OR, 4.8; $95 \%$ CI, 1.178 to $19.580 ; p=0.029$ ). Freeman et al. ${ }^{37}$ reported that both moderate numbers of cannulation attempts (6 to 15 ) and excessive numbers ( $>15)$, as well as the use of more than one contrast injection into the pancreas, influenced the development of pancreatitis. A recent multicenter study and meta-analyses also demonstrated that an early precut facilitated successful selective biliary cannulation and significantly reduced the incidence or severity of PEP. ${ }^{35-38,52}$

\section{Precut fistulotomy versus conventional precut sphincterotomy}

In a retrospective study, Abu-Hamda et al..$^{53}$ compared three techniques: precut fistulotomy with occasional PS; precutting with a blended current without PS; and precutting with a pure cutting current and frequent PS. The success rates for each technique were not statistically different $(95.5 \%, 95.7 \%$, and 89.6\%), and the PEP rates also did not differ significantly ( $0 \%$,
6\%, and 3\%). Precut fistulotomy reduced the risk of PEP compared with the conventional precut method. Another retrospective study by Katsinelos et al. ${ }^{54}$ compared precut fistulotomy, conventional precut, and transpancreatic sphincterotomy. In that study, the success rates were $92.3 \%, 97.7 \%$, and $100 \%$ for the three techniques, respectively, and the PEP rates were $2.6 \%, 20.9 \%$, and $22.4 \%$, respectively $(p=0.001$ ). Precut fistulotomy resulted in a significantly lower rate of PEP compared with conventional precut or transpancreatic sphincterotomy. Another RCT by Mavrogiannis et al. ${ }^{29}$ also showed that the occurrence of PEP was significantly lower with precut fistulotomy than with precut papillotomy ( $0 \%$ vs. $7.6 \%, p<0.05$ ), without any difference in the technical success.

Theoretically, precut fistulotomy can prevent direct injury to the PD or edematous change of the AV compared with other conventional precut techniques where the precut starts at the orifice of the AV. Thus, according to the ESGE guideline, precut fistulotomy may be recommended as a precut technique. ${ }^{12}$

\section{Transpancreatic septotomy/sphincterotomy}

Transpancreatic septotomy involves incision of the biliary-pancreatic septum, which separates the PD from the bile duct, through the PD orifice..$^{55}$ The septum is located between the PD and the CBD. Difficult biliary cannulation may be related to duct blockage by the ampulla septum in cases where the guidewire repeatedly enters the $\mathrm{PD}^{56}$ Unlike a freehand technique, such as an NK, papillary transpancreatic septotomy can be performed in patients where cannulation is difficult or PD cannulation occurs. In papillary transpancreatic septotomy, a papillotome is used, and there is no need to exchange devices after the introduction of the guidewire into the PD. When unintentional PD cannulation has occurred repeatedly, the septotomy or sphincterotomy is relatively easy. Wire-assisted septotomy can be performed after introducing a guidewire into the $\mathrm{PD}$, followed by sphincterotomy, maintaining the direction of the bile duct at 11 oclock. By cutting through the septum between the PD and bile duct, the biliary and pancreatic orifices are both rendered visible. ${ }^{56-58}$ The overall technical success of this procedure was reported to range from $85 \%$ to $97.5 \%$, with a lower incidence of complications. ${ }^{31,55,58-60}$ Another useful and safe option for pancreatic sphincterotomy is to precut along the PS, following the placement of a prophylactic PS when unintentional PD cannulation occurs. In these cases, the second procedure (i.e., the precut from the orifice) is relatively easy and more comfortable for the operator than a freehand technique. Precut along the PS also prevents or minimizes PEP and acts as a guide to facilitate selective biliary access. ${ }^{3}$ 


\section{Summary of precut-related complications}

As described above, the precut-related complications, such as PEP, bleeding, and perforation, have now been reported to be similar to those associated with conventional sphincterotomy in experienced hands. PEP in particular, one of the most severe complications, is reported to have a similar rate to that in conventional sphincterotomy. However, prolonged and repeated cannulation procedures prior to precut with inexperienced hands may increase the risk of PEP. Among various techniques, precut fistulotomy reduced the risk of PEP compared with the conventional precut method, and precut following placement of prophylactic PS also reduced the rate of PEP. ${ }^{50-53,61}$ However, still more comparative studies with transpancreatic septotomy, taking into account the type of devices and criteria such as difficult cannulation, will be needed to clarify the question of complications.

\section{SUMMARY}

The selection of alternative procedures in cases of difficult cannulation should consider the next step, especially in patients with a high risk of PEP. In cases of frequent unintentional PD cannulation, DGC, precut, or transpancreatic septotomy with the guidance of a guidewire as well as a prophylactic PS may be useful. Moreover, when selective biliary access is difficult, despite frequent meaningful contact with the papilla or prolonged cannulation times without unintentional PD cannulation, an early precut fistulotomy is preferable. However, some aspects of the precut timing remain controversial. The definition of what constitutes a "difficult" cannulation is uncertain, as is the level of training (expertise) required to perform precutting. More data from large-scale multicenter studies are needed to resolve these issues. According to the ESGE guidelines, the criteria for a difficult biliary cannulation are more than 5 minutes of cannulation time, more than five instances of meaningful papillary contact, or more than one instance of unintentional PD cannulation. However, the evidence on which these are based is weak. ${ }^{12} \mathrm{Fi}-$ nally, criteria for the primary precut technique in the absence of standard cannulation may be also needed for patients at high risk of PEP.

\section{CONCLUSIONS}

Various primary or rescue methods are available to facilitate selective biliary or pancreatic access. As a freehand technique, a precut fistulotomy is a useful technique to facilitate biliary access in cases of difficult biliary cannulation, without PD cannulation. In repeated unintentional PD cannulation, DGC, transpancreatic septotomy, and prophylactic PS-guided precut sphincterotomy can be attempted. Recently, if the primary approach (first choice) fails, EUS-guided endoscopy can be attempted in addition to the traditional percutaneous approach. The role of EUS in difficult cannulations is now expanding, and both EUS-guided rendezvous and antegrade drainage can be attempted in the same ERCP unit. However, the criteria for what constitutes difficult cannulation, the timing of rescue procedures, and the experience level of the operator remain to be defined clearly. Based on the current literature, the application of a stepwise algorithm rather than a single technique is needed to facilitate biliary or pancreatic access during ERCP without increasing complications.

\section{Conflicts of Interest}

The authors have no financial conflicts of interest.

\section{REFERENCES}

1. Testoni PA, Testoni S, Giussani A. Difficult biliary cannulation during ERCP: how to facilitate biliary access and minimize the risk of post-ERCP pancreatitis. Dig Liver Dis 2011;43:596-603.

2. Lee TH, Jung YK, Park SH. Preparation of high-risk patients and the choice of guidewire for a successful endoscopic retrograde cholangiopancreatography procedure. Clin Endosc 2014;47:334-340.

3. Lee TH, Park do H. Endoscopic prevention of post-endoscopic retrograde cholangiopancreatography pancreatitis. World J Gastroenterol 2014;20:16582-16595.

4. Siegel JH, Pullano W. Two new methods for selective bile duct cannulation and sphincterotomy. Gastrointest Endosc 1987;33:438-440.

5. Tse F, Yuan Y, Moayyedi P, Leontiadis GI. Guidewire-assisted cannulation of the common bile duct for the prevention of post-endoscopic retrograde cholangiopancreatography (ERCP) pancreatitis. Cochrane Database Syst Rev 2012;12:CD009662.

6. Mariani A, Giussani A, Di Leo M, Testoni S, Testoni PA. Guidewire biliary cannulation does not reduce post-ERCP pancreatitis compared with the contrast injection technique in low-risk and high-risk patients. Gastrointest Endosc 2012;75:339-346.

7. Kawakami H, Maguchi H, Mukai T, et al. A multicenter, prospective, randomized study of selective bile duct cannulation performed by multiple endoscopists: the BIDMEN study. Gastrointest Endosc 2012;75:362372.e1.

8. Katsinelos P, Paroutoglou G, Kountouras J, et al. A comparative study of standard ERCP catheter and hydrophilic guide wire in the selective cannulation of the common bile duct. Endoscopy 2008;40:302-307.

9. Artifon EL, Sakai P, Cunha JE, Halwan B, Ishioka S, Kumar A. Guidewire cannulation reduces risk of post-ERCP pancreatitis and facilitates bile duct cannulation. Am J Gastroenterol 2007;102:2147-2153.

10. Bailey AA, Bourke MJ, Williams SJ, et al. A prospective randomized trial of cannulation technique in ERCP: effects on technical success and post-ERCP pancreatitis. Endoscopy 2008;40:296-301.

11. Lee TH, Park DH, Park JY, et al. Can wire-guided cannulation prevent post-ERCP pancreatitis? A prospective randomized trial. Gastrointest Endosc 2009;69(3 Pt 1):444-449.

12. Testoni PA, Mariani A, Aabakken L, et al. Papillary cannulation and sphincterotomy techniques at ERCP: European Society of Gastrointestinal Endoscopy (ESGE) Clinical Guideline. Endoscopy 2016;48:657-683.

13. Cheung J, Tsoi KK, Quan WL, Lau JY, Sung JJ. Guidewire versus con- 
ventional contrast cannulation of the common bile duct for the prevention of post-ERCP pancreatitis: a systematic review and meta-analysis. Gastrointest Endosc 2009;70:1211-1219.

14. Masci E, Mariani A, Curioni S, Testoni PA. Risk factors for pancreatitis following endoscopic retrograde cholangiopancreatography: a meta-analysis. Endoscopy 2003;35:830-834.

15. Lella F, Bagnolo F, Colombo E, Bonassi U. A simple way of avoiding post-ERCP pancreatitis. Gastrointest Endosc 2004;59:830-834.

16. Dumonceau JM, Deviere J, Cremer M. A new method of achieving deep cannulation of the common bile duct during endoscopic retrograde cholangiopancreatography. Endoscopy 1998;30:S80.

17. Freeman ML, Guda NM. ERCP cannulation: a review of reported techniques. Gastrointest Endosc 2005;61:112-125.

18. Maeda S, Hayashi H, Hosokawa O, et al. Prospective randomized pilot trial of selective biliary cannulation using pancreatic guide-wire placement. Endoscopy 2003;35:721-724.

19. Herreros de Tejada A, Calleja JL, Díaz G, et al. Double-guidewire technique for difficult bile duct cannulation: a multicenter randomized, controlled trial. Gastrointest Endosc 2009;70:700-709.

20. Huang L, Yu QS, Zhang Q, Liu JD, Wang Z. Comparison between double-guidewire technique and transpancreatic sphincterotomy technique for difficult biliary cannulation. Dig Endosc 2015;27:381-387.

21. Kim CW, Chang JH, Kim TH, Han SW. Sequential double-guidewire technique and transpancreatic precut sphincterotomy for difficult biliary cannulation. Saudi J Gastroenterol 2015;21:18-24.

22. Yoo YW, Cha SW, Lee WC, Kim SH, Kim A, Cho YD. Double guidewire technique vs transpancreatic precut sphincterotomy in difficult biliary cannulation. World J Gastroenterol 2013;19:108-114.

23. Freeman ML, Nelson DB, Sherman S, et al. Complications of endoscopic biliary sphincterotomy. N Engl J Med 1996;335:909-918.

24. Cotton PB, Garrow DA, Gallagher J, Romagnuolo J. Risk factors for complications after ERCP: a multivariate analysis of 11,497 procedures over 12 years. Gastrointest Endosc 2009;70:80-88.

25. Martin DF, Tweedle DE. Retroperitoneal perforation during ERCP and endoscopic sphincterotomy: causes, clinical features and management. Endoscopy 1990;22:174-175.

26. Enns R, Eloubeidi MA, Mergener K, et al. ERCP-related perforations: risk factors and management. Endoscopy 2002;34:293-298.

27. Lee TH, Bang BW, Park SH, Jeong S, Lee DH, Kim SJ. Precut fistulotomy for difficult biliary cannulation: is it a risky preference in relation to the experience of an endoscopist? Dig Dis Sci 2011;56:1896-1903.

28. Harewood GC, Baron TH. An assessment of the learning curve for precut biliary sphincterotomy. Am J Gastroenterol 2002;97:1708-1712.

29. Mavrogiannis C, Liatsos C, Romanos A, Petoumenos C, Nakos A, Karvountzis G. Needle-knife fistulotomy versus needle-knife precut papillotomy for the treatment of common bile duct stones. Gastrointest Endosc 1999;50:334-339.

30. Kasmin FE, Cohen D, Batra S, Cohen SA, Siegel JH. Needle-knife sphincterotomy in a tertiary referral center: efficacy and complications. Gastrointest Endosc 1996;44:48-53.

31. Goff JS. Long-term experience with the transpancreatic sphincter pre-cut approach to biliary sphincterotomy. Gastrointest Endosc 1999;50:642-645.

32. Foutch PG. A prospective assessment of results for needle-knife papillotomy and standard endoscopic sphincterotomy. Gastrointest Endosc 1995;41:25-32.

33. de la Morena EJ, Domínguez M, Lumbreras M, Opio V, Moyano E, Garćia Alvarez J. Self-training in needle-knife sphincterotomy. Gastroenterol Hepatol 2000;23:109-115.

34. Rollhauser C, Johnson M, Al-Kawas FH. Needle-knife papillotomy: a helpful and safe adjunct to endoscopic retrograde cholangiopancreatography in a selected population. Endoscopy 1998;30:691-696.

35. Sundaralingam P, Masson P, Bourke MJ. Early precut sphincterotomy does not increase risk during endoscopic retrograde cholangiopancreatography in patients with difficult biliary access: a meta-analysis of randomized controlled trials. Clin Gastroenterol Hepatol 2015;13:17221729.e2.

36. Navaneethan U, Konjeti R, Venkatesh PG, Sanaka MR, Parsi MA. Early precut sphincterotomy and the risk of endoscopic retrograde cholangiopancreatography related complications: an updated meta-analysis. World J Gastrointest Endosc 2014;6:200-208.

37. Freeman ML, DiSario JA, Nelson DB, et al. Risk factors for post-ERCP pancreatitis: a prospective, multicenter study. Gastrointest Endosc 2001;54:425-434.

38. Bailey AA, Bourke MJ, Kaffes AJ, Byth K, Lee EY, Williams SJ. Needle-knife sphincterotomy: factors predicting its use and the relationship with post-ERCP pancreatitis (with video). Gastrointest Endosc 2010; 71:266-271.

39. Siegel JH. Precut papillotomy: a method to improve success of ERCP and papillotomy. Endoscopy 1980;12:130-133.

40. Sherman S, Ruffolo TA, Hawes RH, Lehman GA. Complications of endoscopic sphincterotomy. A prospective series with emphasis on the increased risk associated with sphincter of Oddi dysfunction and nondilated bile ducts. Gastroenterology 1991;101:1068-1075.

41. Kaffes AJ, Sriram PV, Rao GV, Santosh D, Reddy DN. Early institution of pre-cutting for difficult biliary cannulation: a prospective study comparing conventional vs. a modified technique. Gastrointest Endosc 2005;62:669-674.

42. Horiuchi A, Nakayama Y, Kajiyama M, Tanaka N. Effect of precut sphincterotomy on biliary cannulation based on the characteristics of the major duodenal papilla. Clin Gastroenterol Hepatol 2007;5:11131118.

43. Dowsett JF, Polydorou AA, Vaira D, et al. Needle knife papillotomy: how safe and how effective? Gut 1990;31:905-908.

44. O'Connor HJ, Bhutta AS, Redmond PL, Carruthers DA. Suprapapillary fistulosphincterotomy at ERCP: a prospective study. Endoscopy 1997;29:266-270.

45. Akaraviputh T, Lohsiriwat V, Swangsri J, Methasate A, Leelakusolvong S, Lertakayamanee $\mathrm{N}$. The learning curve for safety and success of precut sphincterotomy for therapeutic ERCP: a single endoscopist's experience. Endoscopy 2008;40:513-516.

46. Robison LS, Varadarajulu S, Wilcox CM. Safety and success of precut biliary sphincterotomy: is it linked to experience or expertise? World J Gastroenterol 2007;13:2183-2186.

47. Huibregtse K, Katon RM, Tytgat GN. Precut papillotomy via fine-needle knife papillotome: a safe and effective technique. Gastrointest Endosc 1986;32:403-405.

48. Lee TH, Hwang SO, Choi HJ, et al. Sequential algorithm analysis to facilitate selective biliary access for difficult biliary cannulation in ERCP: a prospective clinical study. BMC Gastroenterol 2014;14:30.

49. Choudhary A, Winn J, Siddique S, et al. Effect of precut sphincterotomy on post-endoscopic retrograde cholangiopancreatography pancreatitis: a systematic review and meta-analysis. World J Gastroenterol 2014;20:4093-4101.

50. Cennamo V, Fuccio L, Zagari RM, et al. Can early precut implementation reduce endoscopic retrograde cholangiopancreatography-related complication risk? Meta-analysis of randomized controlled trials. Endoscopy 2010;42:381-388.

51. Gong B, Hao L, Bie L, Sun B, Wang M. Does precut technique improve selective bile duct cannulation or increase post-ERCP pancreatitis rate? A meta-analysis of randomized controlled trials. Surg Endosc 2010;24:2670-2680.

52. Mariani A, Di Leo M, Giardullo N, et al. Early precut sphincterotomy for difficult biliary access to reduce post-ERCP pancreatitis: a randomized trial. Endoscopy 2016;48:530-535.

53. Abu-Hamda EM, Baron TH, Simmons DT, Petersen BT. A retrospective comparison of outcomes using three different precut needle knife techniques for biliary cannulation. J Clin Gastroenterol 2005;39:717-721.

54. Katsinelos P, Gkagkalis S, Chatzimavroudis G, et al. Comparison of three types of precut technique to achieve common bile duct cannula- 
tion: a retrospective analysis of 274 cases. Dig Dis Sci 2012;57:3286-3292.

55. Goff JS. Common bile duct pre-cut sphincterotomy: transpancreatic sphincter approach. Gastrointest Endosc 1995;41:502-505.

56. Miao L, Li QP, Zhu MH, et al. Endoscopic transpancreatic septotomy as a precutting technique for difficult bile duct cannulation. World J Gastroenterol 2015;21:3978-3982.

57. Wang P, Zhang W, Liu F, et al. Success and complication rates of two precut techniques, transpancreatic sphincterotomy and needle-knife sphincterotomy for bile duct cannulation. J Gastrointest Surg 2010;14:697-704.

58. Weber A, Roesch T, Pointner S, et al. Transpancreatic precut sphincterotomy for cannulation of inaccessible common bile duct: a safe and successful technique. Pancreas 2008;36:187-191.

59. Kahaleh M, Tokar J, Mullick T, Bickston SJ, Yeaton P. Prospective evaluation of pancreatic sphincterotomy as a precut technique for biliary cannulation. Clin Gastroenterol Hepatol 2004;2:971-977.

60. Catalano MF, Linder JD, Geenen JE. Endoscopic transpancreatic papillary septotomy for inaccessible obstructed bile ducts: comparison with standard pre-cut papillotomy. Gastrointest Endosc 2004;60:557-561.

61. Song BJ, Kang DH. Prevention of postendoscopic retrograde cholangiopancreatography pancreatitis: the endoscopic technique. Clin Endosc 2014;47:217-221 